\title{
"Uwoy Gayang" and the Indigenous Populations Collaborative Effort against Covid 19 Pandemic: A Case Study of the Naneng Heritage Village
}

\author{
Juan Moshe M. Duyan
}

Received: 19 Nov 2021; Received in revised form: 11 Dec 2021; Accepted: 20 Dec 2021; Available online: 31 Dec 2021 (C2021 The Author(s). Published by Infogain Publication. This is an open access article under the CC BY license (https://creativecommons.org/licenses/by/4.0/).

\begin{abstract}
This case study sought to discover the collaborative efforts developed/ implemented by the local officials and tribal leaders, of Brgy. Naneng, Tabuk City, Kalinga in their COVID-19 prevention and containment program. In response to COVID-19, Barangay Naneng, Tabuk CIty, sealed off community access to non-residents and require 14-day quarantine for any returning residents who left the community and enacted more severe self-imposed travel restrictions, including the banning of all visitors and denial of return access to residents leaving temporarily. The panglakayans however were not able to contribute very much in the implementation and execution of some programs because they were no longer allowed to go out after the lockdown on March 16, 2020 was implemented except for their strong advise to practice an indigenous tradition called "Uwoy Gayang". 6 months after the lockdown on March 16, 2020 Naneng remains to be Covid Free.It is found that the indigenous people of Brgy. Naneng Tabuk City simply followed the prescribed protocols, implemented lockdown and observed the quarantine period for returning resident. They however added an indigenous way of dealing with Covid19 which is the Uwwoy Gayang which is not scientifically proven but is believed to increase their resiliency.
\end{abstract}

Keywords-Indigenous, Covid19, Case Study, Lockdown.

\section{INTRODUCTION}

\section{Background of the Study}

Indigenous people of Kalinga share common characteristics that make them remarkably exposed to COVID-19. As noted, Indigenous populations have higher rates of extreme poverty, morbidity, and mortality than their non-indigenous counterparts. These position puts them at high risk of complexities and death from COVID-19.

These people have unique sensitivity to COVID-19 for numerous reasons. Other than respiratory and other health ailments raising the risk of COVID-19 death, indigenous communities often have least access to clean water, soap, personal protective equipment (PPE), and public disinfection. Local medical services are often funded poorly. Hospitals and clinics are unable meet the high demand for COVID-19 testing and treatment in the general population, let alone for indigenous communities located farther away, who often encounter shame or discrimination.
Long travel to regional hospitals or clinics means added possibility for virus transmission on congested public transportation or other means of conveyance. The incapacity to pay for medical services farther prevents access when not included under government health programs.

Local practices can also further virus transmission. Collectivity is a core that covers the daily life in many indigenous cultures, from extended family ties, public labor and production, food distribution, and other group activities. This collectivity is and can hinder adherence to social distancing measures. Most of the member of indigenous people are already dependent to town markets for their provision such as food, medicine and government sponsored cash programs because most of their traditional source of subsistence vanished. Moreover, as most of the industries and businesses involving indigenous communities closed at the onset of the COVID-19 pandemic, food shortage has become a serious impediment to sustaining livelihoods. 
Tribal elders or the "panglakayans" are at particularly high risk of COVID-19 death due to their age, existing health conditions, weakness, and immune deficiency. Elders are essential for preserving indigenous culture and language among rapid globalization, so their inherent loss could end in cultural or linguistic extinction. These so called "panglakayans" are considered living archives; language, ritual, and mythology specialists; role models and mentors; and keepers in multigenerational households.

Moreover, because indigenous people usually occupy protected territories abundant in biodiversity and natural resources, accelerated resource exploitation feigns perils to indigenous livelihoods and lives. Illegal logging or mining activities might also be progressing during the pandemic because of limited government monitoring and implementation, resulting in even more sweeping exploitation of indigenous territories and disastrous encounters with indigenous communities than before the pandemic.

Barangay Naneng recorded 0 cases since the declared lockdown on March 16,2020.

Only 11 were sent for home quarantine and 4 in Barangay Isolation Unit.

This study seeks to find out and describe the collaborative efforts in terms of implementation strategies and local considerations of tribal leaders, and local officials of Brgy. Naneng, Tabuk City, Kalinga in their COVID-19 prevention and containment program.

\section{Conceptual Framework}

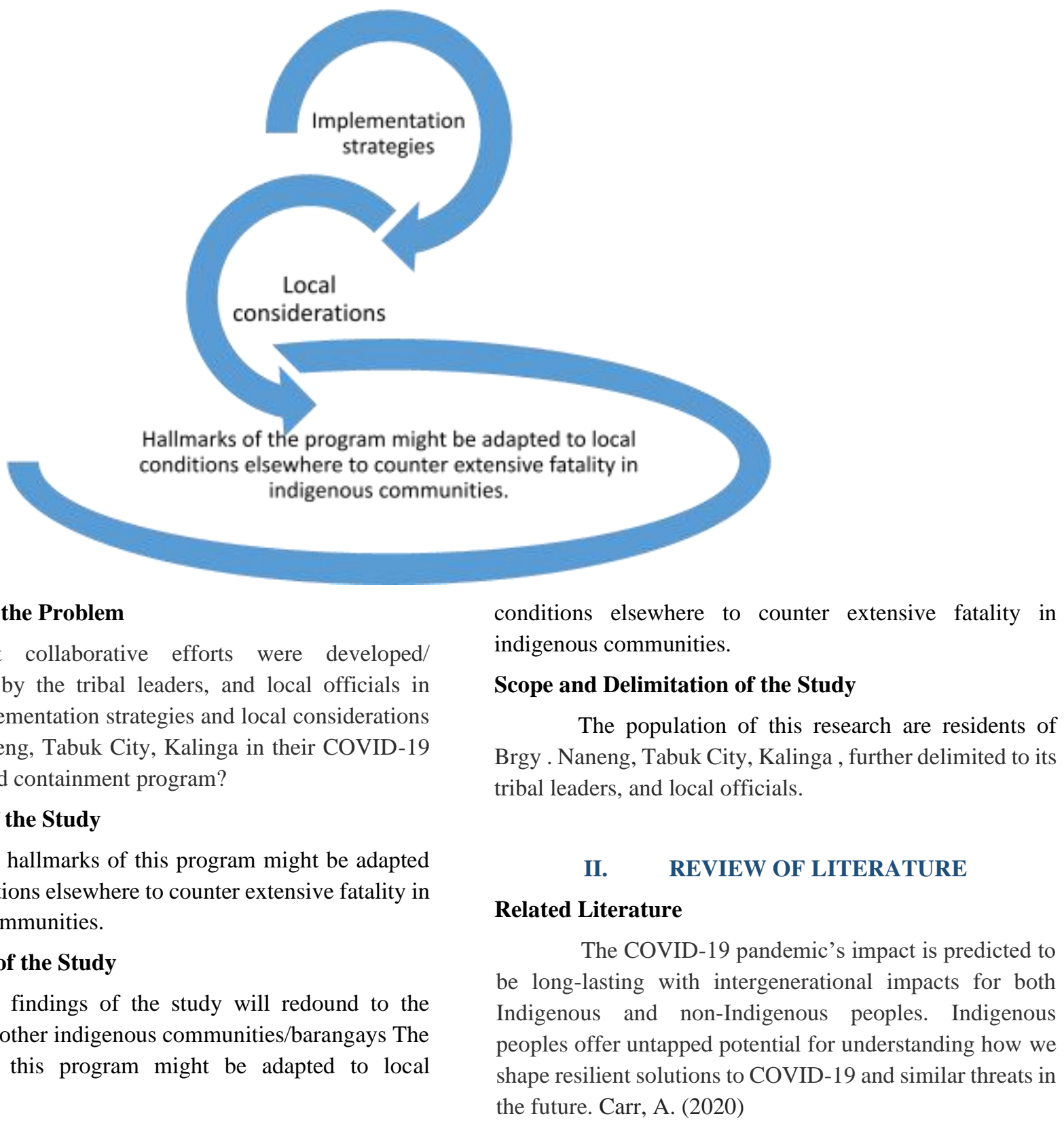

\section{Statement of the Problem}

What collaborative efforts were developed/ implemented by the tribal leaders, and local officials in terms of implementation strategies and local considerations of Brgy. Naneng, Tabuk City, Kalinga in their COVID-19 prevention and containment program?

\section{Objectives of the Study}

The hallmarks of this program might be adapted to local conditions elsewhere to counter extensive fatality in indigenous communities.

\section{Significance of the Study}

The findings of the study will redound to the benefit of the other indigenous communities/barangays The hallmarks of this program might be adapted to local conditions elsewhere to counter extensive fatality in digenous communities.

\section{Scope and Delimitation of the Study}

The population of this research are residents of Brgy . Naneng, Tabuk City, Kalinga , further delimited to its tribal leaders, and local officials.

\section{REVIEW OF LITERATURE}

The COVID-19 pandemic's impact is predicted to be long-lasting with intergenerational impacts for both Indigenous and non-Indigenous peoples. Indigenous peples offer untapped potential for understanding how we the future. Carr, A. (2020) 
Indigenous and traditional peoples can be expected to be especially vulnerable to severe acute respiratory syndrome-coronavirus 2 (SARS-CoV-2), the virus that causes

COVID-19. In addition to their history of susceptibility to epidemics, Pringle, H. (2015)

A case study design may be used when the researcher cannot manipulate the behavior of the informants in the study and when the study focuses on answering the questions on how and why. Zanial described a case study as a detailed investigation of people, events, and relationships tied by a uniting factor, which helps the readers comprehend complex issues.

\section{DEFINITION OF TERMS}

COLLABORATIVE- produced or conducted by two or more parties working together.

CORONAVIRUS DISEASE (COVID-19) -is an infectious disease caused by a new strain of coronavirus. The virus can cause a range of symptoms, ranging from mild illness to pneumonia. Symptoms of the disease are fever, cough, sore throat and headaches. In severe cases difficulty in breathing and deaths can occur.

HALLMARK- a distinctive feature, especially one of excellence.

INDIGENOUS POPULATIONS- are communities that live within, or are attached to, geographically distinct traditional habitats or ancestral territories, and who identify themselves as being part of a distinct cultural group, descended from groups present in the area before modern states were created and current borders.

RESILIENCE- the capacity to recover quickly from difficulties;toughness.

\section{METHODOLOGY}

\section{Locale of the Study}

The study will be conducted in Brgy . Naneng, Tabuk City, Kalinga

\section{Research Design}

This research study used a case study research design that will focus on the collaborative efforts that were developed/ implemented by the tribal leaders, and local officials of Brgy . Naneng, Tabuk City, Kalinga in their COVID-19 prevention and containment program.The researcher will also use the method of triangulation as an additional method of data analysis and to check the consistency and reliability of data through interviews.

\section{Respondents/informants/research participants}

The population of this research are local officials of Brgy . Naneng, Tabuk City, Kalinga.

The researcher selected informants from the barangay officials and health workers of Naneng. There is no limit or specified number on how many informants should comprise a purposive sample, for as long as the vital information is acquired (Bernard, 2002)Among the barangay officials; the researcher sought to interview atleast 5 but due to the ongoing travel restrictions the researcher was only able to reach 2, Barangay Captain Rommel Balunggay herein referred to as Informant 1 and Barangay midwife Mary Anne de la Paz as Informant2 - using an interview guide adopted by the researcher from the study of Kaplan, H. S., Trumble, B. C., Stieglitz, J., Mamany, R. M., Cayuba, M. G., Moye, L. M., \& Thompson, R. C. (2020) Purposive sampling technique is otherwise known as judgment sampling. It is a non-random technique which is not reliant to the theories or fixes numbers of the informant (Tongco, 2007).

\section{Instrumentation}

The primary data of this study will be from interviews, while the secondary data is from literature reviews. The interview question are adopted from the study Voluntary collective isolation as a best response to COVID-19 for indigenous populations? by Kaplan et al. Interviews are useful for exploratory studies of which, the unstructured interviews are flexible and will give the researcher the freedom to formulate new questions according to the situation of talks with interviewees also they are ideal forms for unpredictable situations and for when respondents provide various types of answers.

\section{Data Gathering}

The researcher sought help from the Barangay Captain of Naneng, Tabuk City,

Kalinga, to locate the key informants for the research.

Before gathering the data, the researcher made sure that the participants give their consent, and with the help of some research assistants, the researcher conducted the interview and data gathering.

\section{Data Analysis}

In addition to the interview conducted, a detailed observation was carried out by the researcher, recording the crucial individual participant's body movements, countenance, and habitual gestures. 


\section{RESULTS AND DISCUSSION}

\section{On Coordination of Barangay Officials and tribal leaders}

According to Informant 1, Barangay Naneng's Implementation Strategies included discussions about existing plans handed down to them by the Local Government Unit of Tabuk. The panglakayans participated in their decision to implement a lockdown in the barangay in their capacity as Lupon members. The tribal leaders however were not able to contribute very much in the implementation and execution of some programs because they were no longer allowed to go out after the lockdown on March 16, 2020 was implemented except for their strong advise to practice an indigenous tradition called "Uwoy Gayang".

Uwoy gayang is a palm leaf hanged on the door of the houses believed to serve as seal against sickness. Informant 1 said his ancestors has been doing the so called Uwoy gayang every time an epidemic hits their village. The hanging of the leaf is done during sunset "pagsipnget" and people should avoid asking questions "giginok" while someone is doing it.

Informant 1 said that although he cannot directly say that the 0 case of Barangay Naneng is due to the Uwoy gayang practice, he believes that the resiliency of the indigenous people of Naneng despite the pandemic can be attributed to it.

\section{On Joint Decision Making}

One crucial element was preventing outsiders from entering Naneng territory. According to Informant 1 they were the first barangay to implement lockdown in the City. Villages organized groups of volunteers to organize and guard physical blockades on entry. Another critical element was to regulate the interactions of villagers with nonresidents. Most assemblages resulted in a barangay level consent that no one should leave the territory and go to an area with disease risk unless there was an emergency. So that local considerations made includes the legal implications and possible tribal practices issues and capacity to collectively isolate; cultural customs regarding decision making.

There was also an agreement regarding the need for a 14-day quarantine in several key entries points to the Naneng territory for any resident who leaves and then returns to the barangay. The idea of quarantine was assumed related to some traditional practices. Considerable debate centered on the need for also separating individuals showing symptoms and, specially, the preparation of shelters for quarantine facilities. There was also much conversation regarding the protection of older community members, primarily people with disabilities.

\section{On Knowledge and Information}

In order for the community to fully understand the nature, implications, signs and symptoms of Covid 19, meetings were held in native dialect. Constant reminders were made thru public announcement by barangay officials roaming around. They posted safety measures, printed on tarpaulins on the Barangay main gate, stores and nearby gasoline. Participant 2 added that he also suggested that there were advisories to the community of the proper use of Facebook information because some posts on Facebook are misleading and fake.

\section{On Coordination with the provincial government and Department of Health}

Coordination with Philippine National Police and military personnel's implementing the General Community quarantine ordered by the National government, the Kalinga provincial hospital and the COVID-19 Inter agency task force, the office of the Congressman, Provincial Local Government and City Local Government is a very important tasks of the barangay official and the tribal leaders. According to Participant 1, this coordination enabled their barangay to obtain government-approved permits to rapidly travel to Bulanao, Tabuk City to hold meetings and to request for health workers, medicines, and PPE to the Barangay Naneng, Tabuk City. Their implementation strategies include recognition of subsisting COVID-19 control procedures; required help from the provincial government and Department of Health and delivery and implementation of community isolation decisions.

Some Civic organizations and private individuals, particularly the former residents of Naneng who are residing abroad donated some food supplies directly to Naneng residents.

\section{On Procurement of and training in the use of PPE}

Participant 2 said, they (as healthworkers were given PPE) by the City Health Office for their use when visiting the Barangay Isolation Unit located at Naneng National Highschool where the Local Stranded Individuals were brought for 14days quarantine. The barangay did not see the need to procure PPE's instead Informant 1 opted to buy vitamins distributed to children ages $0-12$ at the onset of the pandemic to help boosts and strengthen their immune system.

\section{On Primary care in the barangay health unit for non- COVID-19 patients to avoid exposure in the hospital}

According to Particpant 2 there were designated areas for the provision of treatment to non-covid 19 patients they also have medical staff but no diagnostic equipment to 
indicate whether the patient is Covid or Non covid patient. It was also observed that all throughout the lockdown period no one availed of their medical facility except for a 1 child birth.

\section{On Isolation support}

Implementation Strategies for isolation support includes roadblock located at the entry point of Barangay Naneng manned by 2 Barangay Tanods, 1 healthcare worker, 1 barangay official and some volunteers to secure the flow of food and basic necessities in and out of the barangay. Food supply were abundant, aside from the locally grown supplies of rice and vegetables, the aid from the national and local government were given and donations from civic organizations and private individuals overflowed.

\section{On Contact Tracing of suspected and confirmed cases}

The low population density expedites the isolation and contact-tracing of suspected and confirmed cases, as of 2015 Census the total population is 691. Most of which are already residing in the urban areas of Tabuk like Dagupan or Bulanao and some are abroad. At present, there are about 1800 people living within the barangay according to Informant 1 only 5 to 10 people were granted ECQ pass that enables them to travel in and out of the barangay to buy necessities. 6 months after the lockdown on March 16, 2020 Naneng remains to be Covid Free.

\section{Summary}

In response to COVID-19, Barangay Naneng, Tabuk CIty, sealed off community access to non-residents and require 14-day quarantine for any returning residents who left the community and enacted more severe selfimposed travel restrictions, including the banning of all visitors and denial of return access to residents leaving temporarily.

Evaluating local knowledge and information about COVID-19 is necessary. Added indispensable component is encouraging and recognizing dynamic collective decision making by the communities themselves, including all important stakeholders, such as barangay official and tribal leaders, city and provincial local government and public health officials, and any other entities associated in controlling the spread of pandemic such as the Inter Agency Task Force. If communities resolve to isolate collectively, economic, medical, and logistical assistance might be needed to make isolation possible. The procurement and instruction in the use of PPE is another fundamental element, as is a plan for treatment of persistent or serious illnesses other than COVID-19 to assure that urgent cases are managed, while sustaining the isolation plan.

\section{CONCLUSION}

The dangers, difficulties, and prospects for strategic responses faced by indigenous communities partake many traits with those encountered by communities everywhere in the world, because of features of COVID-19 itself. The indigenous people of Brgy. Naneng Tabuk City simply followed the prescribed protocols, implemented lockdown and observed the quarantine period for returning resident. They however added an indigenous way of dealing with Covid19 which is the Uwwoy Gayang which is not scientifically proven but is believed to increase their resiliency.

\section{RECOMMENDATION}

The capacity to provide resources daily is necessary for community isolation. Land and use rights by indigenous communities are, therefore, essential to guarantee reliance on subsistence-related pursuit.

Autonomy can expedite making community decisions that can be reinforced by government and tribal authorities, including restricting movement in and out of the territory. It is recommended that tribal self-determination should be acknowledged by the government as an asset for many indigenous populations.

Cultural norms strong family ties and community gatherings are a typical platforms for collective decision making. Moreover, low population density expedites isolation and contact-tracing. These causes of resilience can be utilized to the advancement of strategies for prevention and mitigation of COVID-19 fatality in indigenous populations.

\section{REFERENCES}

[1] Bernard, H. 2(002) Research Methods in Anthropology: Qualitative and quantitative methods. 3rd edition. AltaMira Press, Walnut Creek, California.

[2] Carr, A. (2020). COVID-19, indigenous peoples and tourism: a view from New Zealand. Tourism Geographies, 1-12.

[3] Kaplan, H. S., Trumble, B. C., Stieglitz, J., Mamany, R. M., Cayuba, M. G., Moye, L. M., ... \& Thompson, R. C. (2020). Voluntary collective isolation as a best response to COVID19 for indigenous populations? A case study and protocol from the Bolivian Amazon. The Lancet.

[4] Pringle, H. (2015). How Europeans brought sickness to the New World. Science, 348.

[5] Teegavarapu, Sudhakar \& Summers, Joshua \& Mocko, Gregory. (2008). Case Study Method for Design Research: A Justification. Proceedings of the ASME Design Engineering Technical Conference

[6] Tongco M. (2007) Purposive sampling as a tool for informant selection. Ethnobotany Research \& Applications 5:147-158. 
[7] Zainal, Z. (2007). Case Study as a Research Method. Retrieved February 12, 2019 from https://goo.gl/pty1xQ/

\section{APPENDICES}

Interview questions:

What are your Implementation Strategies and Local Considerations in terms of the following areas?

$\checkmark$ Coordination of tribal leaders

$\checkmark$ Knowledge and information

$\checkmark$ Joint decision making
Coordination with the provincial government and Department of Health

Procurement of and training in the use of PPE

$\checkmark$ Primary care in the barangay health unit for nonCOVID-19 patients to avoid exposure in the hospital

Isolation support

Contact tracing of suspected and confirmed cases Estimated Budget

\begin{tabular}{|c|l|l|l|}
\hline & Qty. & Unit Cost (P) & Total Cost (P) \\
\hline I. MOOE & & & \\
\hline a. Publication Expenses & & & $12,000.00$ \\
\hline b. Transportation & & $1,000.00$ & $\mathbf{1 2 , 0 0 0 . 0 0}$ \\
\hline Grand Total & & & $\mathbf{1 , 0 0 0 . 0 0}$ \\
\hline
\end{tabular}

\section{ANNEX CERTIFICATION OF ORIGINALITY, RELEVANCE, COMPLETENESS AND COMPETENCE}

I JUAN MOSHE M. DUYAN hereby attest to the originality of this research proposal and/or extension entitled

\section{"INDIGENOUS POPULATIONS COLLABORATIVE}

\section{EFFORT AGAINST COVID 19 PANDEMIC: A CASE STUDY OF THE NANENG HERITAGE VILLAGE}

" and has cited properly all the references used. I understand that plagiarism is the act of taking and using another's ideas and works and passing them off as one's own. These include explicitly copying the whole work of another person and/or using some parts of their work without proper acknowledgement and referencing. That I commit that all deliverables and the final output emanating from this proposal shall be of original content. I shall use appropriate citations in referencing other works from various sources. That I fully understand that violation from this attestation and commitment shall subject me to the consequences and shall be dealt with accordingly by the Kalinga State University and concerned agencies.

Project Leader: JUAN MOSHE M. DUYAN

Signature over Printed Name

Date

This is to certify that the above stated research proposal and/or extension project was reviewed by the College Research Council and/or College Extension Council and the recommendations were already incorporated by the proponent/s. That it complies with the requirements in terms of format and substance.

Research Chairman/Extension Chairman: JUAN MOSHE M. DUYAN

Signature over Printed Name

Date

This is to certify that I had reviewed to the best of my knowledge and ability the abovementioned research proposal and/or extension project is worthy to be recommended for funding for it is in line with the objectives of the program/s offered in our college and in the competence of the proponent/s.

College Dean: JOHN JOHN C. VENUS, MPA

Signature over Printed Name

Date 